Proc. Indian Acad. Sci. (Earth Planet. Sci.), Vol, 90, Number 2, July 1981, pp, 155-160, - Printed in India.

\title{
Palaeoclimatic inferences from the behaviour of radiocarbon dates of carbonates from sand dunes of Rajasthan
}

\author{
R V KRISHNAMURTHY, D P AGRAWAL, V N MISRA* and \\ S N RAJAGURU* \\ Physical Research Laboratory, Ahmedabad 380 009, India \\ * Deccan College, Pune 411 006, India
}

MS received 9 May 1980; revised 22 April 1981

\begin{abstract}
Radiocarbon dates on pedogenic $\mathrm{CaCO}_{3}$, accumulated at various depths in a stabilised dune at Budha Pushkar, Rajasthan, show inversion with respect to 'stratigraphy'. Occurrence of younger carbonates overlain by older ones at various levels, is interpreted in terms of a shift in climatic conditions causing pedogenic carbonates to be leached to greater depths. Based on this model, several wetter regions during the last 6000 years have been identified. The most significant shift from a dry to a wet phase seems to have taken place between 5000 and 4500 years ago. Conclusions drawn from this study is in agreement with that based on pollen data and extends this method as a potential palaeoclimatic indicator.
\end{abstract}

Keywords. Palaeoclimate; radiocarbon dates; Budha Pushkar dunes; precipitation index; carbonates.

\section{Introduction}

During pedogenesis, calcium carbonate generated in the soil-horizon is deposited in the sub-soil by leaching effects, giving rise to the so-called $\mathrm{K}$ horizon, root-casts and 'calichified plants' or 'rhizo concretions' (Birkeland 1974; Reeves 1976; Hubert 1978). The pedogenic carbonate is formed mostly by the chemical combination of carbon and oxygen from the atmosphere and calcium supplied by weathering of parent materials (minerals) and/or plant decomposition. Critical radiocarbon dating of such carbonates has been carried out to chronicle the process of pedogenesis (Williams and Polach 1971). Pedogenic carbonates have, however, received only limited attention as palaeoclimatic indicators. This paper examines the possibility of using the ${ }^{14} \mathrm{C}$ date suite from Budha Pushkar dune site for climatic inferences.

\section{Ares of investigation}

Budha Pushkar ( $74^{\circ} 36^{\prime}$ E., $26^{\circ} 30^{\prime}$ N.), about $15 \mathrm{~km}$ northwest of Ajmer lies in the semi-arid central Rajasthan situated in a valley between two parallel ranges of hills and is one of the few freshwater lakes of the region.

The sand dunes adjoining the lake are considerably large and appear to be of more than one period. Conspicuous among them are the stabilised brown 
and yellowish dunes, the latter apparently overlying the other. Earlier work has demonstrated that this region experienced late Quaternary climatic changes, although there is no unanimity regarding the degree of these changes as discernible from the stabilised dunes (Allchin et al 1972; Agrawal et al 1978).

The area is devoid of older geological carbonate rocks, the reported rocks being biotite schist and quartzite. The carbonates occur in fairly large sizes which cannot be carried by migrating dunes. In the present study, samples of calcium carbonate were collected from a yellowish type of dune by digging a $3 \mathrm{~m}$ deep trench. Calcium carbonate occurs as a thin crust at the top, indicating the stabilisation of the dune, and in discrete layers of root-casts, etc. down the profile.

\section{Experimental details}

Representative samples of root-casts were cleansed to remove adhering material and subjected to mild hydrochloric acid treatment for few minutes. This ensured removal of surface layers, the most probable centres of possible contamination. Samples were then washed, dried, powdered and assayed for ${ }^{14} \mathrm{C}$ activity (Agrawal et al 1965).

\section{Discussion}

The results (table 1) are plotted as a function of 'depth' in figure 1. Although the accuracy of dates on carbonates is still unsettled, one can place greater

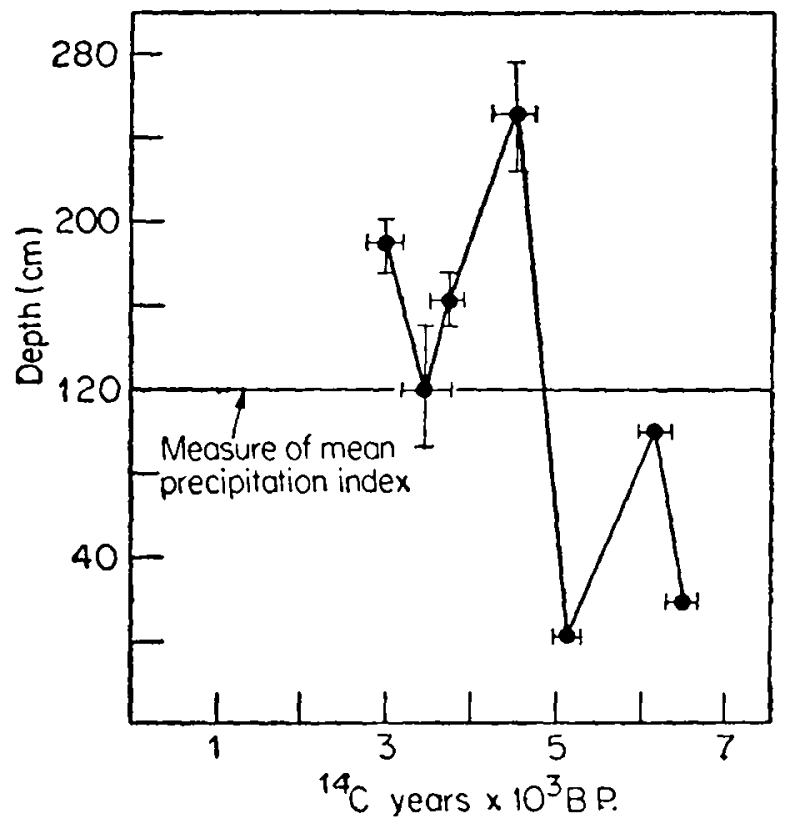

Figure 1. Plot of "C dates (years B. P.) versus depth for the yellowish dune at Budha Pushkar. Bars on the date axis indicate one standard deviation. Depths of carbonates dated are taken here as a measure of precipitation at a particulat period. 
Table 1. 1'C dates on soil carbonates from Budha Pushkar yellow dune.

\begin{tabular}{|c|c|c|c|}
\hline Sample No. & Location & $\begin{array}{l}\text { Depth below } \\
\text { surface in } m\end{array}$ & $\begin{array}{l}{ }^{14} \mathrm{C} \text { age in years } B . P . \\
\tau \frac{1}{2}=5730 \text { years }\end{array}$ \\
\hline PRL-562 & Trench & Surface & $5030 \pm 170$ \\
\hline PRL-563 & $"$ & 0.2 & $6490 \pm 140$ \\
\hline PRL-564 & ", & 1.0 & $6200 \pm 170$ \\
\hline PRL-565 & " & $1-1.5$ & $3520 \pm 230$ \\
\hline PRL-566 & , & $1.5-1.75$ & $3710 \pm 160$ \\
\hline PRL-567 & $"$ & $1.75-2.0$ & $2980 \pm 100$ \\
\hline PRL-568 & ", & $2.25-2.75$ & $4550 \pm 150$ \\
\hline
\end{tabular}

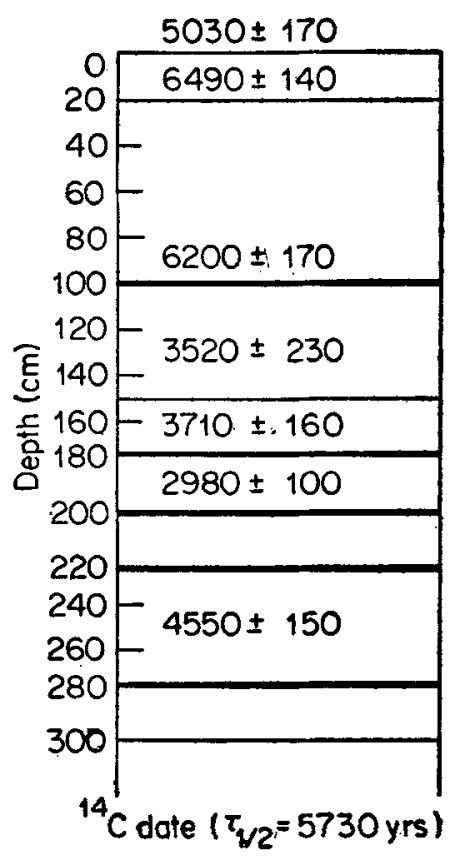

Figure 2. Schematic section of the yellow dune showing inversion of radiocarbon dates. This inversion may be explained by fluctuation in precipitation leading to carbonate remobilisation.

confidence in the present data as the dates, despite the $3 \mathrm{~m}$ depth, show very narrow scatter. Since the area is devoid of older geological carbonate rocks, the reported rocks being biotite schist and quartzite, contribution by dead primary carbonates can be neglected. Moreover, the fact that the youngest carbonate date reported for an arid zone is as old as 2200 years has been suggested as an evidence for minimal contamination with environmental ${ }^{14} \mathrm{C}$.(Williams and Polach 1969). Also the carbonates occur in fairly large sizes which cannot be carried by migrating dunes. The striking reversal of dates with respect to 


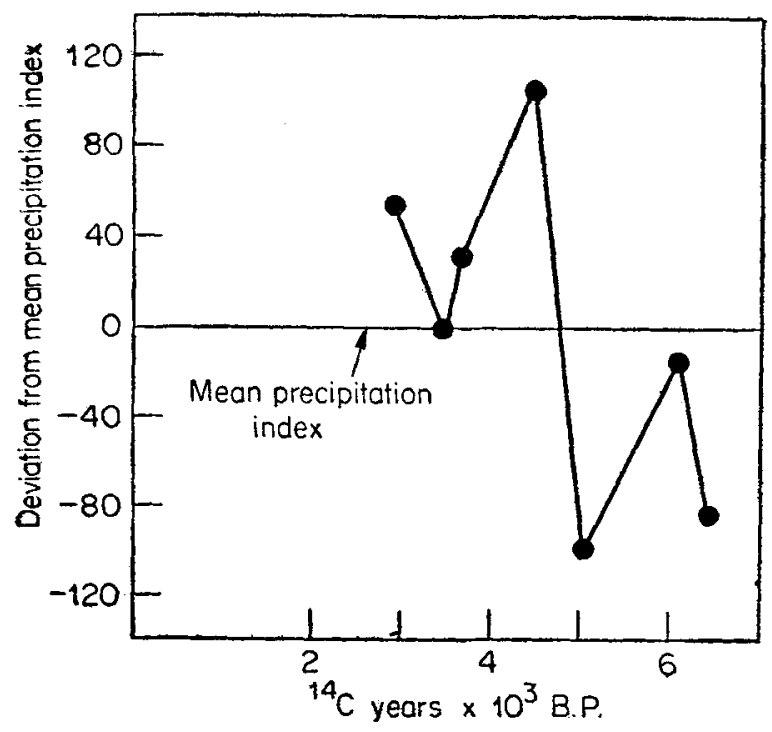

Figure 3. Plot showing deviation from a mean precipitation index, obtained by averaging over the entire depth profile studied. For example, precipitation around 4500 years B. P. was four times greater than that around 5000 years B. P. and twice greater than that around 3500 years $B . P$.

stratigraphy (figure 2) is noteworthy. In the model to explain these "reversals", it is assumed that calcium carbonate formed during pedogenesis, is remobilised to greater depths during periods when precipitation exceeded evaporation. A deeper penetration of moisture (viz. higher precipitation) will be reflected by carbonate migration to greater depths. Transportations to the final depth of deposition is achieved by successive steps of dissolution and reprecipitation. Therefore, the ${ }^{14} \mathrm{C}$ age on a pedogenic carbonate will at least provide an average age for that layer. Moreover, this average age will be closer to the true age on a radiocarbon time-scale, since the soil solution movement would be relatively fast in a sandy medium. This would also ensure minimal secondary processes affecting the ${ }^{14} \mathrm{C}$ age.

Since the carbonate formation is assumed to have taken place in a pre-existing dune, 'depths' in effect indicate the degree of soil solution transport caused by varying degrees of precipitation. It can therefore be taken as a 'moisture movement index' or loosely 'precipitation index'. Figure 3 shows the deviation about the mean of that index; the mean being obtained by averaging over the entire profile. Although this 'index' carries little physical significance, it provides a better visual presentation. It is also evident that the conclusions discussed below will not be affected whether one uses the index curve (figure 3) or a simple age vs depth curve (figure 1).

Based on the present data, the following conclusions can be drawn:

(i) The stabilisation of the dune took place around 6500 years before present (B. P.), marking a relatively wet phase. After a relatively drier 
phase of non-deposition of pedogenic carbonates, conditions became wetter again from about 5000 years B.P. which continued with minor fluctuations until about 3000 years B.P.

(ii) The most dramatic transition from drier to wetter phases took place between 5000 and 4500 years ago which continued with marginal variations until 3000 years B. P.

(iii) Absence of carbonate deposits younger than about 3000 years might tentatively be interpreted as prevalence of relatively arid conditions since then.

(iv) The dates permit an upper limit for the age of the dune, at least for the $3 \mathrm{~m}$ section, which is unlikely to be much greater than 6000 years. If it were not so, one ought to have come across carbonate accumulations corresponding to earlier wetter periods and subsequently anomalously scattered ${ }^{14} \mathrm{C}$ dates due to mixing. The possibility of older carbonates, indicative of still wetter phases, occurring deeper than $3 \mathrm{~m}$, however, cannot be ruled out at this stage.

Earlier workers have recognised several climatic fluctuations in Rajasthan during the last 10,000 years (Agrawal and Pande 1977). Among the widely accepted work is that based on pollen studies and supported by archaeological evidence (Singh et al 1974). Excellent agreement between the palaeoclimatic inferences from the present and the earlier work is easily seen (table 2).

Thus our work as well as that by Leamy and Rafter (1972) indicate that it is possible to use pedogenic carbonate to obtain valuable palaeoclimatic data that can supplement studies based on other parameters. We are planning to extend this study to other areas in Western Rajasthan.

Table 2. Comparison of climatic sequences in Rajasthan during the last 10,000 years based on the palynological work by Singh et al and the present work.

Key : $X=$ no data

\begin{tabular}{llll}
\hline $\begin{array}{l}{ }^{14} C \text { years B. P. } \\
\tau \frac{1}{2}=5730 \text { years }\end{array}$ & Pollen data & $\begin{array}{l}{ }^{14} \text { C years B P. } \\
\tau \frac{1}{2}=5730 \text { years }\end{array}$ & Present work \\
\hline Before 10,000 & Severe aridity & $X$ & $X$ \\
$10,000-9500$ & Wetter & $X$ & $X$ \\
$9500-5000$ & Slightly drier & 6500 & Wetter \\
\multicolumn{1}{c}{$X$} & $X$ & $6500-5000$ & Relatively dry \\
$5000-3700$ & Sudden increase & $5000-4500$ & $\begin{array}{l}\text { Sudden increase in } \\
\text { in wetness }\end{array}$ \\
$3700-3500$ & in wetness & $4500-3500$ & Relatively dry \\
$3500-3000$ & Short dry period & $3500-3000$ & Relatively wet \\
3000 & Marginally wetter & 3000 & Arid \\
\hline
\end{tabular}




\section{Acknowledgements}

The authors express their thanks to Shri N B Vaghela for multifarious help. Drs R K Pant and A K Singhvi and Shri R Ramesh went through the paper critically and offered valuable comments.

\section{References}

Agrawal D P and Pande B M (eds) 1977 Ecology and Archaeology of Western India (New Delhi : Concept Publishers)

Agrawal D P, Kusumgar S and Lal D 1965 Curr. Sci. 34394

Agrawal D P, Datta P S, Dhir R P, Krishnamurthy R V, Misra V N, Rajaguru S N and Thomas K T 1978 Natl. Seminar on Quat. Environment, Baroda

Allchin B, Hegde K T M and Goudie A 1972 Man 7541

Birkeland P W 1974 Pedology, Weathering and Geomorphological Research

(London and New York : Oxford University Press)

Hubert J F 1978 Palaeogeagr. palaeoclimato. palaeoecol. 24151

Leamy M L and Rafter T A 1972 Proc. Eighth Int. Conf. on Radiocarbon Dating (eds.)

T A Rafter and T Grant Tayler (Wellington : Royal Society) p. 353

Reeves C R 1976 Caliche: Origin, Classification, Morphology and Uses (Lubbock : Estacado Press)

Singh G, Joshi R D, Chopra S K and Singh A B 1974 Philos. Trans. R. Soc. London 267457

Williams G E and Polach H A 1969 Earth Planet. Sci. Lett. 7240

Williams G E and Polach H A 1971 Geol. Soc. Am. Bull. 823069 